\title{
Uma análise de sistemas para Planejamento Financeiro Familiar: um mapeamento sistemático da literatura
}

\section{An analysis of Family Financial Planning Systems: a systematic literature mapping}

\author{
Vanessa Martha Pereira ${ }^{1}$, Avanilde Kemczinski ${ }^{1,2}$ \\ ${ }^{1}$ PPGCA, ${ }^{2}$ PPGECMT, Departamento de Ciência da Computação - Centro de Ciências \\ Tecnológicas - Universidade do Estado de Santa Catarina (UDESC) \\ Joinville, Santa Catarina - Brasil \\ vanessa.martha@gmail.com, avanilde.kemczinski@udesc.br
}

\begin{abstract}
Family financial planning is part of the routine of all families. Information systems can assist in this process with resources that involve all members of the family. This article presents a systematic mapping literature, to identify information systems and strategies used in family financial planning. As a result, 40 information systems were identified and observed that in many cases computer systems are not used, as these do not understand the genuine needs of the family, such as the collaboration of the members. The family financial planning area needs further studies in the development of information systems that support the family's social relationships in financial planning.
\end{abstract}

Keywords. Systematic Literature Mapping; Family Financial Planning; Collaborative Systems.

Resumo. O planejamento financeiro familiar faz parte da rotina de todas as famílias. Sistemas de informação podem auxiliar neste processo com recursos que envolvam todos os membros da familia. Este artigo apresenta um mapeamento sistemático da literatura, com o objetivo de identificar sistemas de informação e estratégias utilizadas no planejamento financeiro familiar. Como resultado, foi identificado 40 sistemas de informação e observado que em muitos casos não são utilizados sistemas computacionais, pois estes não compreendem as necessidades genuínas da família, como a colaboração dos membros. A área de planejamento financeiro familiar necessita de mais estudos no desenvolvimento de sistemas de informação que apoiem as relações sociais da família no planejamento financeiro.

Palavras-Chave. Mapeamento Sistemático da Literatura; Planejamento Financeiro Familiar; Sistemas Colaborativos.

\section{Introdução}

Um dos grandes desafios das famílias é a criação e manutenção do planejamento financeiro familiar (PFF). Com as ocupações e as atividades do dia a dia, o planejamento financeiro muitas vezes é esquecido ou postergado. Esta situação reflete diretamente na saúde financeira das famílias. 
Foi realizada uma pesquisa no Brasil [Serasa Experian 2019] em março de 2019 que confirmou esta situação. A pesquisa registrou que 63 milhões de consumidores estavam com dívidas atrasadas e/ou negativadas. Este número representa 40,3\% da população adulta do país e ressalta que mesmo com os benefícios de se realizar o PFF, ainda em muitos casos é ignorado por parte da população.

Uma das causas relacionadas ao endividamento, segundo Brito et al. (2018), é o baixo conhecimento financeiro, pois faz com que as pessoas tenham dificuldades para acumular reservas e aumentar o patrimônio. Embora a tecnologia possa ser uma grande aliada neste processo, na literatura foi possível averiguar que faltam recursos em sistemas de informação para o PFF, como características proativas (recomendar ações necessárias para melhorar o PFF) [Gao et al. 2006]. Por causa da falta de recursos, em muitos casos os usuários que fazem uso deste tipo de sistema de informação, abandonam após um curto período [Kaye et al. 2014] [Snow and Vyas 2015a].

Os autores acrescentam que o PFF, em muitos casos, é uma atividade realizada colaborativamente pela família, e pode ser apoiada por sistemas de informação ou não, como a utilização de aplicativos para celular ou recursos sem a necessidade de tecnologia como agendas e calendários de papel [Snow and Vyas 2015b].

De acordo com Laudon e Laudon (2014), um Sistema de Informação (SI) pode ser definido como "um conjunto de componentes inter-relacionados que coletam (ou recuperam), processam, armazenam e distribuem informações destinadas a apoiar a tomada de decisão, a coordenação e o controle em uma organização".

Neste sentido, o objetivo deste trabalho é contribuir com a sociedade por meio do entendimento de como os sistemas de informação podem melhorar a vida de famílias no planejamento financeiro. Muito além de apresentar subsídios para projetar um sistema de informação de PFF, a proposta é trazer uma reflexão de quais são as necessidades genuínas da família e como um SI pode auxiliar neste processo fomentando o envolvimento deste grupo e apoiando o contexto social de forma responsável.

De igual modo, este estudo está relacionado ao desafio da visão sociotécnica de sistemas de informação, proposto pelos autores Boscarioli et al. (2017), especificamente na perspectiva sistêmica e socialmente consciente para sistemas de informação [Pereira and Baranauskas 2017]. A preocupação com componentes computacionais não deve estar restrita a funções projetadas e a qualidade destes, mas deve se preocupar também com o meio ambiente no qual estão inseridos, assim como as pessoas, os possíveis usos e os efeitos que eles podem desencadear [Pereira and Baranauskas 2017].

Para atender o objetivo proposto, foi realizado um mapeamento sistemático da literatura (MSL) com a metodologia proposta por Petersen et al. (2015). O MSL buscou entender como as famílias realizam o processo do PFF. Estes dados são importantes para entender como se relacionam e quais são as suas necessidades genuínas, desta forma, estes dados podem ser utilizados para o design de um sistema de informação para o PFF. O MSL teve como objetivo principal responder a seguinte questão de pesquisa: "Como tem sido realizado o planejamento financeiro pessoal e/ou familiar?" e entender os sistemas de informação e as estratégias utilizadas pelas famílias neste processo. 
Para um melhor entendimento o artigo foi dividido em seções. Na Seção 2, é apresentada a fundamentação teórica com a definição dos termos relacionados ao planejamento financeiro familiar, sistemas colaborativos e modelo $3 \mathrm{C}$ de colaboração. Na Seção 3, os trabalhos relacionados a este e na Seção 4 a metodologia adotada com o detalhamento das questões de pesquisa, processo de busca e seleção, mapeamento e extração dos dados. Na Seção 5, são apresentados os resultados e na Seção 6, a discussão em que são respondidas as questões de pesquisa. Por fim, na Seção 7 são apresentadas as considerações finais, seguida dos agradecimentos e referências bibliográficas. Após as referências, no Apêndice A estão listadas todas as referências dos artigos utilizados no MSL para extração de dados e análise.

\section{Fundamentação Teórica}

Esta seção apresenta um levantamento bibliográfico dos fundamentos importantes para este trabalho: os termos relacionados ao planejamento financeiro familiar são apresentados na Seção 2.1, sistemas colaborativos na Seção 2.2 e o modelo 3C de colaboração na Seção 2.3.

\subsection{Planejamento Financeiro Familiar}

Existem diferentes termos relacionados ao planejamento financeiro como: gerenciamento financeiro, finanças; gestão das finanças; orçamento doméstico; contabilidade doméstica, entre outros. Alguns destes termos podem ser aplicados tanto no contexto pessoal como familiar, empresarial ou público.

Cherobim e Espejo (2010) definem as finanças pessoais como: "a ciência que estuda a aplicação de conceitos financeiros nas decisões financeiras de uma pessoa ou família. Em finanças pessoais são considerados os eventos financeiros de cada indivíduo". Struwig e Plaatjes (2007) adotaram os termos "finanças pessoais" e "gestão financeira pessoal" em seu trabalho e definiram como um conjunto de atividades, que inclui o planejamento e tomada de decisão, organização, implementação, controle da destinação do lucro e acumulação da riqueza por um indivíduo ou família, tendo como objetivo atingir as metas financeiras eficientemente.

De acordo com Pires (2006), as finanças pessoais estudam e analisam as condições para a compra de bens e serviços, para atingir a satisfação das necessidades e desejos de indivíduos. Os autores complementam que, as finanças familiares seguem a mesma lógica das finanças pessoais, a diferença está na soma de indivíduos, deste modo, quando só um deles tem fonte de renda, as finanças pessoais devem ser geridas de modo a satisfazer as necessidades e desejos de toda a família.

Os autores Gonzalez Junior et al. (2018) frisam que o envolvimento de todos os membros da família e o conhecimento dos objetivos faz com que obtenham resultados positivos para todos, pois a criação e o uso do planejamento deixam de ser uma carga e passam a ser uma ferramenta que maximiza os recursos e minimiza os gastos supérfluos.

Neste contexto, os sistemas colaborativos podem ser utilizados para dar suporte à família por meio da colaboração de todos os membros no processo de planejamento financeiro familiar. A colaboração é o trabalho em conjunto com pessoas para atingir metas explícitas e compartilhadas, através da realização de tarefas ou missões [Laudon and Laudon 2014]. 
Com base nos fundamentos apresentados, para fins desta pesquisa, foi adotado o termo "planejamento financeiro familiar" (PFF), definido como um conjunto de atividades que incluem o gerenciamento das receitas e despesas, planejamento das atividades financeiras atuais e futuras, como orçamento previsto versus o realizado, metas financeiras, tanto para o nível pessoal (individual), quanto familiar (coletivo).

$\mathrm{Na}$ próxima seção são apresentados os fundamentos de sistemas colaborativos, que são essenciais para entender como ocorre sua colaboração e funcionamento. Estes conceitos podem ser aplicados em um sistema de informação para auxiliar a família a realizar o PFF colaborativamente.

\subsection{Sistemas Colaborativos}

O termo Sistemas Colaborativos é a tradução utilizada no Brasil para groupware e Computer Supported Cooperative Work (CSCW), alguns autores consideram como sinônimos e outros atribuem o termo groupware especificamente a sistemas utilizados para auxiliar o trabalho de grupo, e o termo CSCW a sistemas e aos aspectos psicológicos, sociais e organizacionais em um trabalho em grupo [Nicolaci-Da-Costa and Pimentel 2011].

A colaboração é importante em um grupo, é por meio da interação dos membros que ocorre o complemento de capacidades, conhecimentos e esforço dos indivíduos, aumentando a possibilidade de alcançarem melhores resultados, com a apresentação de diversos pontos de vistas na busca de ideias, informações e na resolução de problemas [Fuks et al. 2002]. Além disso, os autores acrescentam que no grupo é possível gerar alternativas e avaliar vantagens e desvantagens, selecionar as melhores alternativas e chegar a uma decisão.

De acordo com Nicolaci-da-Costa e Pimentel (2011), um sistema colaborativo não deve se ater somente ao comando e controle da realização das tarefas, mas deve ser desenvolvido para ser um espaço a ser habitado. Para isso, é necessário compreender o conceito de colaboração, para então desenvolver um sistema colaborativo [Pimentel et al. 2008].

As teorias e os modelos de colaboração auxiliam na projeção e seleção de sistemas que contemplam o trabalho em grupo, por meio do entendimento de como as pessoas colaboram incluindo os aspectos sociais relacionados ao uso de tecnologia [Fuks et al. 2011]. Na próxima subseção será apresentado o modelo 3C de colaboração e sua relação com PFF.

\subsection{Modelo 3C de Colaboração}

O modelo 3C de colaboração é compreendido em 3 dimensões: a comunicação, coordenação e cooperação [Pimentel et al. 2006]. De acordo com Fuks et al. (2011) as dimensões podem ser compreendidas como:

comunicação (comum + ação): contempla negociação e firmação de compromissos, ela pode ser mediada por computador nas interações entre os indivíduos gerenciando transições de estados, diálogos e compromissos;

coordenação (co + ordem + ação): organiza o grupo para que as atividades sejam realizadas de acordo com a ordem estabelecida, no tempo certo e de acordo com as restrições e objetivos; e 
cooperação (co + operar + ação): envolve a realização das atividades gerenciadas pela coordenação em um espaço compartilhado entre os indivíduos.

Enquanto os indivíduos do grupo se comunicam, negociam e tomam decisões sobre imprevistos que ocorrem durante a cooperação, que por sua vez, necessita da comunicação; enquanto se coordenam, tratam conflitos e organizam as atividades para eliminar a perda de comunicação e dos esforços de cooperação [Fuks et al. 2011]. A Figura 1 apresenta como os 3Cs trabalham em conjunto no Modelo 3C para que ocorra a colaboração.

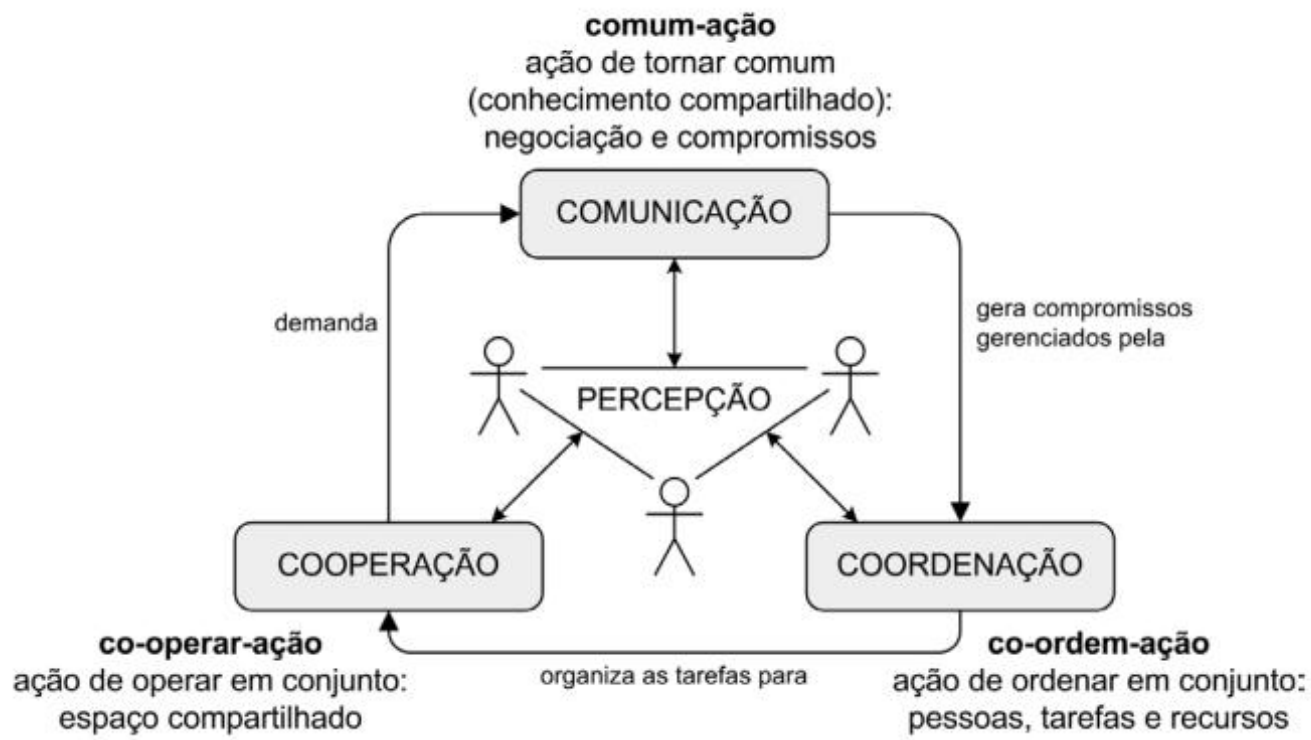

Figura 1. Modelo 3C de colaboração [Fuks et al. 2011].

A percepção é determinante para que ocorra a colaboração, pois é por meio desta, que os indivíduos têm conhecimento e compreendem o que ocorre no grupo. Deste modo, reduz a solidão e o isolamento em trabalhos de grupo, pois o conhecimento e a compressão das atividades realizadas por outros, produz um maior engajamento. [Santos et al. 2011].

Nesse sentido, podemos relacionar e aplicar os conceitos sobre sistemas colaborativos e seus modelos, para elencar as necessidades da família no processo de PFF. Com base nestes fundamentos, na próxima seção o mapeamento sistemático é apresentado. Os fundamentos foram essenciais para a definição dos termos a serem utilizados na string de busca e no processo de seleção de artigos relevantes.

\section{Trabalhos Relacionados}

Até o limite desta pesquisa, não foram encontrados estudos científicos secundários e terciários com o mesmo objetivo deste artigo, especificamente sobre o estudo de sistemas de informação para o planejamento financeiro familiar em veículos da área de Ciências da Computação. Esta descoberta destaca a importância e a contribuição deste trabalho e abre a discussão para que se tenha mais estudos na área de Ciência da Computação, aplicados a uma área específica do conhecimento como Finanças.

Ao realizar buscas foi identificado um trabalho primário dos autores Snow e Vyas (2015b) com o objetivo de identificar como as famílias organizavam e 
gerenciavam as finanças. Os autores realizaram entrevistas com 16 famílias na Austrália, iniciadas com o representante da família desenhando fluxogramas de suas situações financeiras, incluindo fontes de renda, contas, empréstimos e de onde as despesas foram pagas. Todas as famílias foram questionadas sobre (1) como eles colaboraram (ou não colaboraram) na gestão de dinheiro; (2) os sistemas (sistemas de informação ou não) utilizados na sua gestão (por exemplo, programando débitos automáticos, lembretes, armazenamento, frascos de poupança etc.), (3) quaisquer problemas enfrentados na gestão das suas finanças; e (4) as ideias para ferramentas ou aplicações que possam contribuir para a superação desses problemas ou ajudar na sua gestão financeira em geral. Como resultado, concluíram que o foco de grande parte do design de tecnologia na área de planejamento financeiro familiar é o desenvolvimento de novos sistemas de informação, destinados a ajudar as pessoas no orçamento e no planejamento das finanças pessoais. Entretanto, mesmo que estes sistemas de informação ofereçam funcionalidades para o usuário e desempenhem um papel importante na administração do dinheiro em escala pessoal, estes SI não possuíam funcionalidades importantes como a colaboração. Este ponto vai contra o que foi observado pelos autores, que em muitas vezes o PFF era realizado colaborativamente pelas famílias assim como outras tarefas domésticas.

A partir deste trabalho, foram identificadas as palavras chaves e iniciado o processo de busca por trabalhos relacionados. A principal diferença entre o trabalho dos autores Snow e Vyas (2015b) e este, foi a metodologia utilizada. Para se ter uma visão ampla do que está sendo pesquisado e publicado nesta área, foi utilizada a metodologia de mapeamento sistemático da literatura (MSL). O MSL teve como objetivo a busca por estudos primários e responder as questões de pesquisa: como as famílias realizavam o planejamento financeiro, e se utilizavam sistemas de informação colaborativos. A próxima seção apresentará o processo realizado de planejamento e execução do mapeamento sistemático da literatura.

\section{Mapeamento Sistemático da Literatura}

Neste artigo o processo metodológico foi caracterizado por um levantamento bibliográfico. Foi desenvolvido um mapeamento sistemático da literatura (MSL) baseado nas diretrizes de Petersen et al. (2015). Segundo Kitchenham et al. (2004), esta metodologia de pesquisa é uma das mais utilizadas na área de Engenharia de Software. Este tipo de estudo (analisa vários artigos, mas isso é sumarizado em um estudo), através da pesquisa ampla na literatura para encontrar os estudos que respondam à questão de pesquisa definido no MSL e onde foram publicados [Petersen et al. 2015]. A proposta de Petersen et al. (2015) tem como principais etapas do MSL:

1. Definição de questões de pesquisa;

2. Pesquisa de documentos relevantes;

3. Triagem de documentos;

4. Extração de dados;

5. Análise e classificação e

6. Ameaças à validade. 
Após a definição das etapas, o processo de desenvolvimento do protocolo foi planejado e executado. Nas próximas seções serão apresentadas as etapas de planejamento e execução da pesquisa com a definição de suas questões, pesquisa e triagem de documentos, extração e classificação dos dados e as ameaças à validade.

\subsection{Definição das questões de pesquisa}

A definição de questões de pesquisa (QP) é essencial e tem como objetivo guiar o mapeamento sistemático da literatura. Com o objetivo de analisar como é realizado o planejamento financeiro familiar, foi definida como questão principal (QPP): "Como tem sido realizado o planejamento financeiro pessoal e/ou familiar?"

Para compor a resposta da QPP foram definidas 3 questões secundárias:

QS1: “Quais são os sistemas de informação que apoiam o planejamento financeiro pessoal e/ou familiar?";

QS2: "Quais são as estratégias para realizar o planejamento financeiro pessoal e/ou familiar?" e

QS3: "O sistema de informação ou a estratégia adotada, apresenta requisitos colaborativos para o desenvolvimento do planejamento financeiro pessoal e/ou familiar?”.

\subsection{Pesquisa de documentos relevantes}

O processo de busca e seleção de artigos relevantes para o MSL, foi realizado em 3 etapas:

Etapa 1: Busca de estudos relevantes nos Mecanismos de Busca Acadêmico (MBA);

Etapa 2: Aplicação de critérios de inclusão; e

Etapa 3: Aplicação dos critérios de exclusão.

Para a aplicação dos critérios de inclusão na Etapa 2, foi realizada a leitura do título, resumo (artigos em inglês abstract) e palavras chaves dos trabalhos resultantes da Etapa 1. Na Etapa 3 para aplicação dos critérios de exclusão, foi realizada a leitura completa dos trabalhos incluídos na Etapa 2.

A busca por artigos relevantes foi realizada em 5 MBAs: ACM Digital Library, Engineering Village, Science Direct, IEEE Xplore, Scopus e SciELO ${ }^{1}$. Os MBAs foram selecionados, pois estão entre os mais bem avaliados de acordo com Buchinger et al. (2014).

A string de busca foi definida a partir da questão principal de pesquisa e com base nos termos relacionados ao planejamento financeiro familiar (apresentados na Seções 2 e 3). Os termos foram traduzidos para inglês para obter uma melhor performance nas buscas. Foram realizados diversos testes para a definição da string final. Em alguns MBAs foram necessárias adaptações para se adequar ao formato de

${ }^{1}$ ACM Digital Library - http://dl.acm.org

Engineering Village - https://www.engineeringvillage.com/search/quick.url

Science Direct - http://www.sciencedirect.com

IEEE Xplore - $\mathrm{http} / / /$ ieeexplore.ieee.org/Xplore/home.jsp

Scopus - https://www.scopus.com/home.uri

SciELO - http://www.scielo.org/php/index.php 
busca esperado pelo mecanismo. Na Tabela 1 são apresentadas as strings utilizadas em cada MBA e os filtros utilizados. A string principal foi definida como:

("family" OR "personal") AND ("financial planning" OR "finances" OR "budget") AND ("system" OR "tool" OR "framework")

Tabela 1 - Strings de Busca

\begin{tabular}{|c|c|c|}
\hline MBAs & $\begin{array}{l}\text { String de } \\
\text { Busca }\end{array}$ & String após os filtros \\
\hline $\begin{array}{l}\text { ACM } \\
\text { Digital } \\
\text { Library } \\
\text { Science } \\
\text { Direct } \\
\end{array}$ & \multirow{4}{*}{$\begin{array}{l}\text { ("family" OR } \\
\text { "personal") } \\
\text { AND } \\
\text { ("financial } \\
\text { planning" OR } \\
\text { "finances" } \\
\text { OR "budget") } \\
\text { AND } \\
\text { ("system" OR } \\
\text { "tool" OR } \\
\text { "framework") }\end{array}$} & \multirow[t]{2}{*}{$\begin{array}{c}\text { ("family" OR "personal") AND ("financial planning" } \\
\text { OR "finances" OR "budget") AND ("system" OR } \\
\text { "tool" OR "framework") }\end{array}$} \\
\hline $\begin{array}{l}\text { IEEE } \\
\text { Xplore }\end{array}$ & & \\
\hline $\begin{array}{l}\text { Engineering } \\
\text { Village }\end{array}$ & & $\begin{array}{l}(((\text { family" OR "personal") AND ("financial planning" } \\
\text { OR "finances" OR "budget") AND ("system" OR } \\
\text { "tool" OR "framework")) WN KY) + (2019 OR } 2018 \\
\text { OR 2017 OR 2016 OR 2015 OR 2014 OR 2013 OR } \\
\text { 2012 OR 2011 OR 2010 OR 2009 OR 2008 OR } 2007 \\
\text { OR 2006 OR 2005 OR 2004 OR 2003 OR } 2002 \text { OR } \\
\text { 2001 OR 2000) WN YR }\end{array}$ \\
\hline SciELO & & $\begin{array}{l}\text { ("family" OR "personal") AND ("financial planning" } \\
\text { OR "finances" OR "budget") AND ("system" OR } \\
\text { "tool" OR "framework") AND year_cluster:("2013" } \\
\text { OR "2017" OR "2010" OR "2011" OR "2018" OR } \\
\text { "2000" OR "2003" OR "2004" OR "2006" OR "2007" } \\
\text { OR "2012" OR "2014" OR "2015" OR "2001" OR } \\
\text { "2002" OR "2009" OR "2016" OR "2019") }\end{array}$ \\
\hline Scopus & $\begin{array}{c}\text { (family OR } \\
\text { personal) } \\
\text { AND } \\
\text { (financial } \\
\text { planning OR } \\
\text { finances OR } \\
\text { budget) AND } \\
\text { (system OR } \\
\text { tool OR } \\
\text { framework) }\end{array}$ & 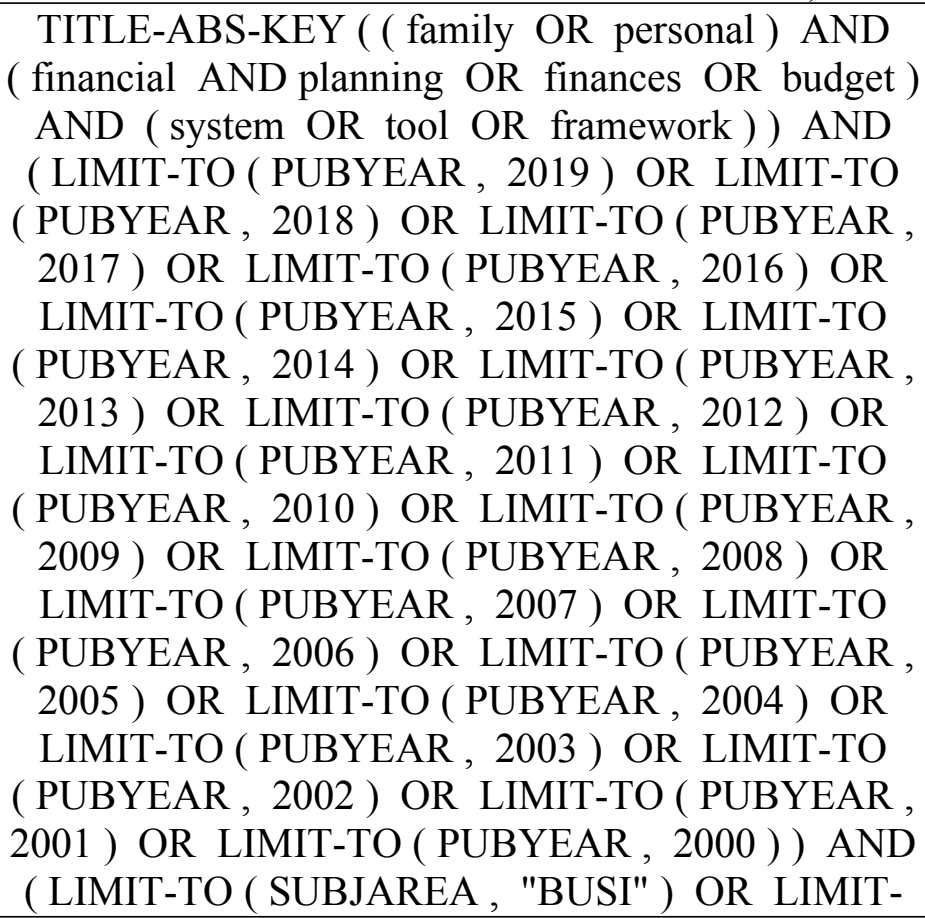 \\
\hline
\end{tabular}




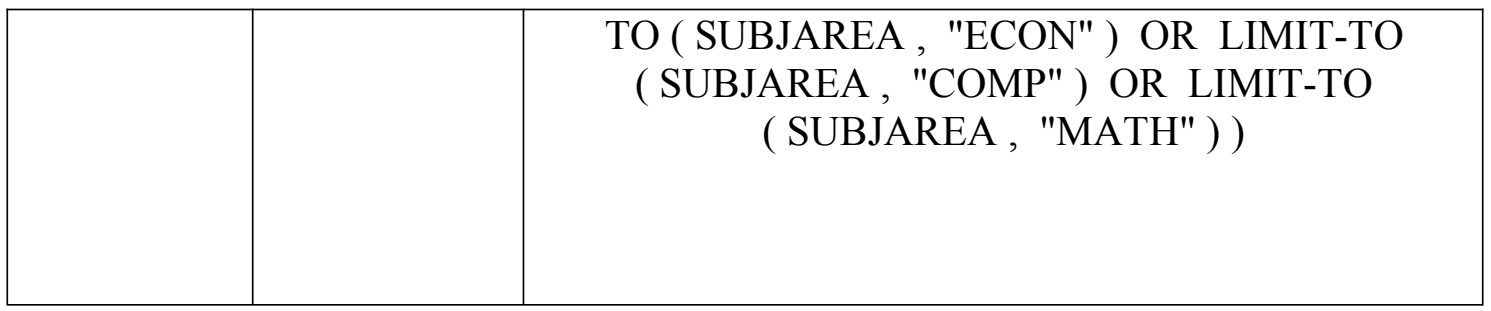

Em todos os MBAs foram utilizados filtros de data para atender o critério de inclusão CI1 (apresentado nos próximos parágrafos). Devido ao grande número de resultados, para o mecanismo Scopus, além do filtro de data, foi necessário limitar por subárea. As áreas selecionadas foram: Business, Management and Accounting; Economics, Econometrics and Finance; Computer Science; e Mathematics.

A busca nos MBAs resultou em 1722 artigos, estes foram analisados para que pudessem ser incluídos ou excluídos da extração de dados. A quantidade de artigos resultante em cada mecanismo de busca pode ser visualizada na Tabela 2.

Tabela 2 - Quantidade de artigos retornados pelos MBAs

\begin{tabular}{|c|c|}
\hline Mecanismo de Busca & Quantidade de artigos \\
\hline SciELO & 594 \\
\hline ACM Digital Library & 477 \\
\hline Science Direct & 240 \\
\hline Engineering Village & 207 \\
\hline IEEE Xplore & 154 \\
\hline Scopus & 50 \\
\hline Total & $\mathbf{1 7 2 2}$ \\
\hline
\end{tabular}

O MBA com o maior número foi SciElo com 594 estudos, seguido da ACM Digital Library com 477 artigos. Após a etapa de pesquisa dos documentos relevantes, foi realizada a triagem desses trabalhos por meio da aplicação de critérios. Na próxima subseção serão apresentados os critérios utilizados e a quantidade de artigos resultantes em cada aplicação.

\subsection{Triagem de documentos}

Para a triagem dos documentos foi realizada a aplicação de critérios de inclusão e exclusão. Os critérios de inclusão (CI) definidos foram:

CI1: Artigos publicados entre 2000 e 2019 - este critério foi automatizado através dos filtros nos MBAs;

CI2: Artigos que abordam o planejamento financeiro pessoal e/ou familiar no título e/ou no resumo do artigo. Outros sinônimos também foram considerados como: finança pessoal/familiar/doméstica, gestão financeira doméstica, orçamento pessoal/familiar/doméstico;

CI3: Artigos com no mínimo 3 páginas - este limite foi devido a identificação de um estudo relevante que possuía 3 páginas;

CI4: Disponíveis para download gratuitamente; e

CI5: Idioma inglês e português.

Para os critérios de exclusão (CE) foram definidos:

CE1: Artigos duplicados, ou seja, retornados em mais de um MBA; 
CE2: Estudos sobre educação financeira ou conhecimento em finanças pessoais e/ou familiar com foco conceitual;

CE3: Estudos que abordem somente planejamento financeiro para a área de investimentos;

CE4: Estudos que não apresentem um sistema de informação ou estratégia para o planejamento financeiro pessoal e/ou familiar; e

CE5: Artigos secundários e terciários - estes estudos não foram adicionados, pois não procuram resolver uma situação específica e sim apresentar o estado da arte ou conclusões de estudos primários. Caso fossem identificados artigos secundários e terciários seriam adicionados os estudos primários analisados $\mathrm{e} o$ artigo principal como um trabalho relacionado.

Ao aplicar os critérios de inclusão nos 1722 artigos encontrados, foram selecionados 52 artigos para aplicação dos critérios de exclusão. A Tabela 3 apresenta a quantidade de artigos selecionados após a aplicação dos critérios de inclusão por mecanismo de busca.

Tabela 3 - Quantidade de artigos selecionados após a aplicação dos CI

\begin{tabular}{|c|c|}
\hline Mecanismo de Busca & Quantidade de artigos \\
\hline Scopus & 22 \\
\hline ACM Digital Library & 15 \\
\hline Engineering Village & 5 \\
\hline Science Direct & 5 \\
\hline IEEE Xplore & 4 \\
\hline SciELO & 1 \\
\hline Total & $\mathbf{5 2}$ \\
\hline
\end{tabular}

Para a aplicação dos critérios de exclusão, foi realizada a leitura completa dos artigos e após a aplicação dos critérios de exclusão foram selecionados 23 artigos para extração e análise de dados. Nas etapas de aplicação dos critérios de inclusão e exclusão, alguns estudos não foram selecionados. A Tabela 4 apresenta o número de artigos não incluídos de acordo com os critérios de inclusão.

Tabela 4 - Artigos não selecionados de acordo com CI

\begin{tabular}{|c|c|}
\hline Critérios de Inclusão & Quantidade de artigos \\
\hline Não relacionados ao tema & 1653 \\
\hline $\begin{array}{c}\text { Não-disponíveis para download } \\
\text { gratuitamente }\end{array}$ & 14 \\
\hline Com menos de 3 páginas & 1 \\
\hline Outros idiomas & 2 \\
\hline Total & $\mathbf{1 6 7 0}$ \\
\hline
\end{tabular}

Do total de 1722 artigos retornados inicialmente, 1670 não atenderam os critérios de inclusão. Desta forma, estes 1670 artigos não foram incluídos para a próxima etapa da pesquisa. Do total de 52 artigos incluídos após os critérios de inclusão, 29 artigos foram removidos com a aplicação dos critérios de exclusão. Desta forma, 23 artigos foram considerados relevantes para a análise e extração de dados.

Na Tabela 5 é apresentada a quantidade de artigos excluídos de acordo com os critérios de exclusão. As informações apresentadas nas Tabelas 4 e 5 são importantes 
para que haja entendimento de como foram analisados os estudos e o processo de busca e seleção até chegar ao resultado.

Tabela 5 - Artigos excluídos de acordo com o critério de exclusão

\begin{tabular}{|l|c|}
\hline \multicolumn{1}{|c|}{ Critérios de Exclusão } & $\begin{array}{c}\text { Quantidade } \\
\text { de artigos }\end{array}$ \\
\hline $\begin{array}{l}\text { Artigos duplicados, ou seja, retornados em mais de } \\
\text { um MBA. }\end{array}$ & 12 \\
\hline $\begin{array}{l}\text { Estudos sobre educação financeira ou conhecimento } \\
\text { em finanças pessoais e/ou familiar. }\end{array}$ & 5 \\
\hline $\begin{array}{l}\text { Estudos que abordem somente o planejamento } \\
\text { financeiro para a área de investimentos. }\end{array}$ & 6 \\
\hline $\begin{array}{l}\text { Estudos que não apresentem um sistema de de } \\
\text { informação ou estratégia para o planejamento } \\
\text { financeiro pessoal e/ou familiar. }\end{array}$ & 6 \\
\hline Artigos secundários e terciários. & 0 \\
\hline Total & $\mathbf{2 9}$ \\
\hline
\end{tabular}

\subsection{Extração de dados}

Nesta etapa para a extração dos dados dos estudos, foi definido um formulário com base em Petersen et al. (2015). Este formulário possui as informações gerais dos artigos e dados para responder as questões de pesquisas do MSL. A Tabela 6 apresenta os dados gerais extraídos dos artigos.

Tabela 6 - Formulário de mapeamento e extração de dados gerais dos artigos

\begin{tabular}{|l|l|}
\hline Item & Valor \\
\hline ID & Código alfanumérico do artigo \\
\hline Título & Título completo do artigo \\
\hline Nome do autor & Nome de todos os autores do artigo \\
\hline Ano & Ano de publicação do artigo \\
\hline Local & $\begin{array}{l}\text { Revista científica, evento ou livro em que } \\
\text { foi publicado }\end{array}$ \\
\hline MBA & $\begin{array}{l}\text { Mecanismo de busca acadêmico em que } \\
\text { foi indexado }\end{array}$ \\
\hline País autores & País dos autores \\
\hline $\begin{array}{l}\text { Universidade } \\
\text { centro de pesquisa }\end{array}$ & $\begin{array}{l}\text { Universidade ou centro de pesquisa em } \\
\text { que o autor faz parte. }\end{array}$ \\
\hline Objetivo & Objetivo do estudo \\
\hline Descrição & $\begin{array}{l}\text { Descrição do estudo como: metodologia } \\
\text { utilizada, detalhamento das etapas e } \\
\text { aplicação do estudo }\end{array}$ \\
\hline Resultados & Resultados do estudo \\
\hline
\end{tabular}


Além dos dados gerais dos artigos, foram mapeados e extraídos dados com o objetivo de responder as questões de pesquisa definidas. A Tabela 7 apresenta os dados mapeados e extraídos de acordo com o número da questão de pesquisa correspondente, desta forma, foram extraídos os dados de sistemas de informação e estratégias.

Tabela 7 - Dados mapeados e extraídos para responder as questões de pesquisa.

\begin{tabular}{|c|c|c|}
\hline \multicolumn{3}{|c|}{ Sistemas de Informação } \\
\hline Nome & Nome do sistema de informação utilizado & QP1 \\
\hline Tipo de plataforma & $\begin{array}{l}\text { Tipo do sistema de informação utilizado como } \\
\text { aplicativo para mobile ou desktop, sistema } \\
\text { WEB ou framework }\end{array}$ & QP1 \\
\hline Descrição & $\begin{array}{l}\text { Descrição do SI: objetivo, principais } \\
\text { características }\end{array}$ & QP1 \\
\hline Aplicação & $\begin{array}{l}\text { Se a aplicação é para uso pessoal (individual) } \\
\text { ou familiar (grupo) }\end{array}$ & QP1 \\
\hline Requisitos funcionais & Descrição dos requisitos funcionais do SI. & QP1 \\
\hline $\begin{array}{l}\text { Requisitos } \\
\text { colaborativos }\end{array}$ & $\begin{array}{l}\begin{array}{l}\text { Descrição detalhada } \\
\text { colaborativos }\end{array} \\
\end{array}$ & QP3 \\
\hline \multicolumn{3}{|c|}{ Estratégias } \\
\hline Nome & Nome da estratégia apresentada. & QP2 \\
\hline Descrição & Descrição da estratégia & QP2 \\
\hline Aplicação & $\begin{array}{l}\text { Se a aplicação é para uso pessoal (individual) } \\
\text { ou familiar (grupo) }\end{array}$ & QP2 \\
\hline $\begin{array}{l}\text { Requisitos } \\
\text { colaborativos }\end{array}$ & $\begin{array}{llll}\begin{array}{l}\text { Descrição detalhada } \\
\text { colaborativos }\end{array} & \text { dos } & \text { requisitos } \\
\end{array}$ & QP3 \\
\hline
\end{tabular}

\subsection{Análise e Classificação}

Após a extração de dados, foi realizada a análise dos artigos relevantes e realizada a classificação em categorias dos sistemas de informação (SI) identificados. Nesta categoria foram adicionadas: ferramentas, softwares, aplicativos, frameworks, modelos conceituais de SI, requisitos funcionais e não funcionais para SI etc. Os SI foram categorizados em:

Sistemas de informação citados pelos autores - esses SI foram somente citados nos artigos como exemplo pelos autores e não houve um estudo de caso envolvido;

Sistemas de informação desenvolvidos pelos autores - SI que foi desenvolvido pelos autores dos artigos;

Sistemas de informação utilizados em estudo de caso - esses SI foram utilizados em um estudo de caso, porém não foram desenvolvidos pelos autores.

Sistemas de informação utilizados por participantes de entrevista - SI levantados através de pesquisa exploratória como a aplicação de questionários e a realização de entrevistas.

Requisitos funcionais e não funcionais para sistemas de informação - requisitos que foram apresentados pelos autores. 
Outra categoria utilizada foram as estratégias. As estratégias são atividades práticas (empíricas) e técnicas utilizadas para o gerenciamento e o planejamento financeiro que não possuem suporte de um sistema de informação no processo. Esta informação é importante para realizar a comparação com os recursos computacionais oferecidos em SI para o PFF versus as estratégias utilizadas por famílias. Assim, este estudo responde se estes sistemas de informação realmente atendem as necessidades genuínas da família no processo de planejamento financeiro. Neste sentido, as estratégias podem servir de base para a proposta de requisitos funcionais e não funcionais no desenvolvimento de um sistema de informação para o PFF.

\subsection{Ameaças à validade}

O processo do MSL foi realizado por pesquisador júnior sob a orientação de um pesquisador sênior, assim a avaliação dos artigos foi realizada de forma manual de acordo com o julgamento dos pesquisadores. Para assegurar que o processo de seleção fosse imparcial, as questões de pesquisa e os critérios de inclusão e exclusão foram definidos antes do início do MSL. A pesquisa foi realizada no período de 2017 a 2019.

A escolha dos termos utilizados na construção da string foi feita para serem os mais genéricos possíveis. O termo "planejamento financeiro familiar" foi definido e adotado após a análise dos resultados, assim na string de busca e nas questões de pesquisa foram utilizados os termos pessoal (no inglês, personal) e familiar (no inglês, family). Para o termo planejamento financeiro, foram incluídas as variações em inglês: financial planning, finances e budget. Para as variações de sistemas de informação foram utilizados os termos em inglês: system, tool e framework.

Não foram incluídos termos relacionados a colaboração, pois o objetivo foi entender de forma ampla como o PFF era realizado. Ao incluir termos como CSCW, collaborative, a string de busca não trouxe um número suficiente de artigos relevantes para este estudo. Para classificar especificamente sistemas de informação colaborativos, foi incluída uma questão de pesquisa QS3.

As buscas foram automatizadas nos MBAs, através da utilização da string, deste modo, como cada MBA interpretou, a string de busca pode ser considerada uma ameaça, pois estudos relevantes podem não ter sido incluídos. Além da automatização da busca no MBA, a análise dos sistemas de informação apresentada na Seção Resultados, foi realizada entre fevereiro e março de 2020 e novas funcionalidades podem ter sido desenvolvidas após este período.

\section{Resultados}

Inicialmente foram identificados 1722 artigos nos MBAs. Após a aplicação de critérios de inclusão e exclusão, 23 artigos foram selecionados como relevantes para esta pesquisa. A Figura 2 apresenta um resumo das etapas de busca e seleção, bem como os resultados em cada etapa. 
- Busca de artigos relevantes nos MBAs através da string de busca.

Etapa 1

Resultado: 1722 artigos.

- Aplicação dos critérios de inclusão, com base na leitura do título, Etapa $2 \quad$ resumo e palavras-chaves. Resultado: $\mathbf{5 2}$ artigos.

- Aplicação dos critérios de exclusão, com base na leitura completa dos Etapa 3 artigos. Resultado: $\mathbf{2 3}$ artigos.

Figura 2 - Etapas do processo de busca e seleção de estudos relevantes

Os 23 artigos selecionados para extração e análise de dados são descritos ao longo das próximas subseções. Para facilitar o entendimento dos dados extraídos, os artigos receberam um código (a letra $\mathrm{A}$ mais um número sequencial, exemplo: $\mathrm{A} 01$ ), a lista completa com as referências dos artigos selecionados está disponível no Apêndice A - Referências dos artigos identificados no mapeamento sistemático da literatura. A Figura 3 apresenta os anos de publicação dos artigos selecionados.

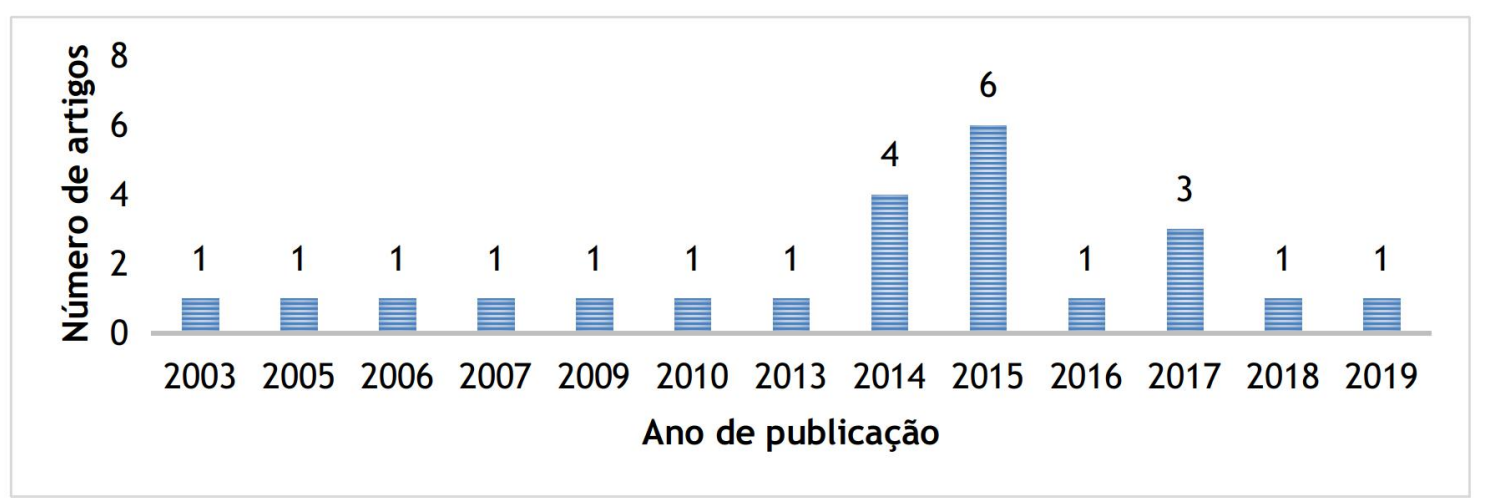

Figura 3 - Quantidade de artigos por ano de publicação

O ano com maior número de publicações é 2015 com 6 artigos, seguido por 2014 com 4 artigos, esse resultado está relacionado com o número de publicações por autor, apresentado na Figura 4. Os dois autores com maior número de publicações, Dhaval Vyas e Stephen Snow, são os principais das publicações de 2015, com o total de 3 publicações no ano. 


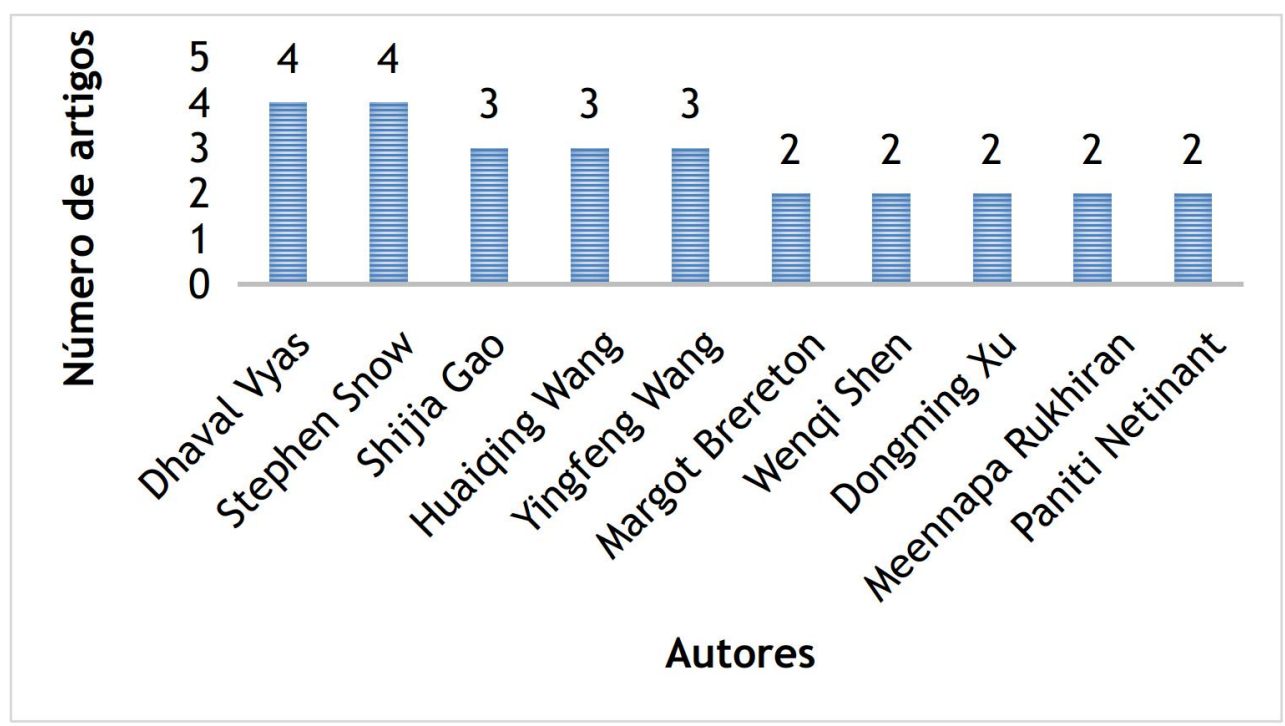

Figura 4 - Quantidade de artigos por autor

Os autores com maior número de artigos publicados são filiados a universidades e departamentos de pesquisas presente nos países: Austrália, Reino Unido, China e Tailândia. Conforme apresentado na Tabela 8, a Austrália é o país com o maior número de universidades envolvidas, são elas: Queensland University of Technology e UQ Business School (University of Queensland).

Tabela 8 - Universidades e departamentos de pesquisas

\begin{tabular}{|l|l|}
\hline Autores & Universidades e departamentos de pesquisas \\
\hline $\begin{array}{l}\text { Dhaval Vyas e Margot } \\
\text { Breton }\end{array}$ & Queensland University of Technology, Australia. \\
\hline Stephen Snow & $\begin{array}{l}\text { Queensland University of Technology, Australia. } \\
\text { University of Southampton, Reino Unido. }\end{array}$ \\
\hline Shijia Gao & $\begin{array}{l}\text { Department of Information Systems, City } \\
\text { University of Hong Kong, Hong Kong, China. } \\
\text { UQ Business School, University of Queensland, } \\
\text { Australia. }\end{array}$ \\
\hline $\begin{array}{l}\text { Huaiqing Wang, Yingfeng } \\
\text { Wang e Wenqi Shen }\end{array}$ & $\begin{array}{l}\text { Department of Information Systems, City } \\
\text { University of Hong Kong, Hong Kong, China. }\end{array}$ \\
\hline Dongming Xu & $\begin{array}{l}\text { UQ Business School, University of Queensland, } \\
\text { Australia. }\end{array}$ \\
\hline $\begin{array}{l}\text { Meennapa Rukhiran e Paniti } \\
\text { Netinant }\end{array}$ & $\begin{array}{l}\text { Tollege of Information and Communication } \\
\text { Technology, Rangsit University, Tailândia. }\end{array}$ \\
\hline
\end{tabular}

Os países dos autores com o maior número de publicação foram os Estados Unidos e Austrália com 5 publicações cada, conforme é exibido na Figura 5. Dentre os 
artigos publicados da Austrália, 5 artigos apresentaram como principais autores Dhaval Vyas e Stephen Snow.

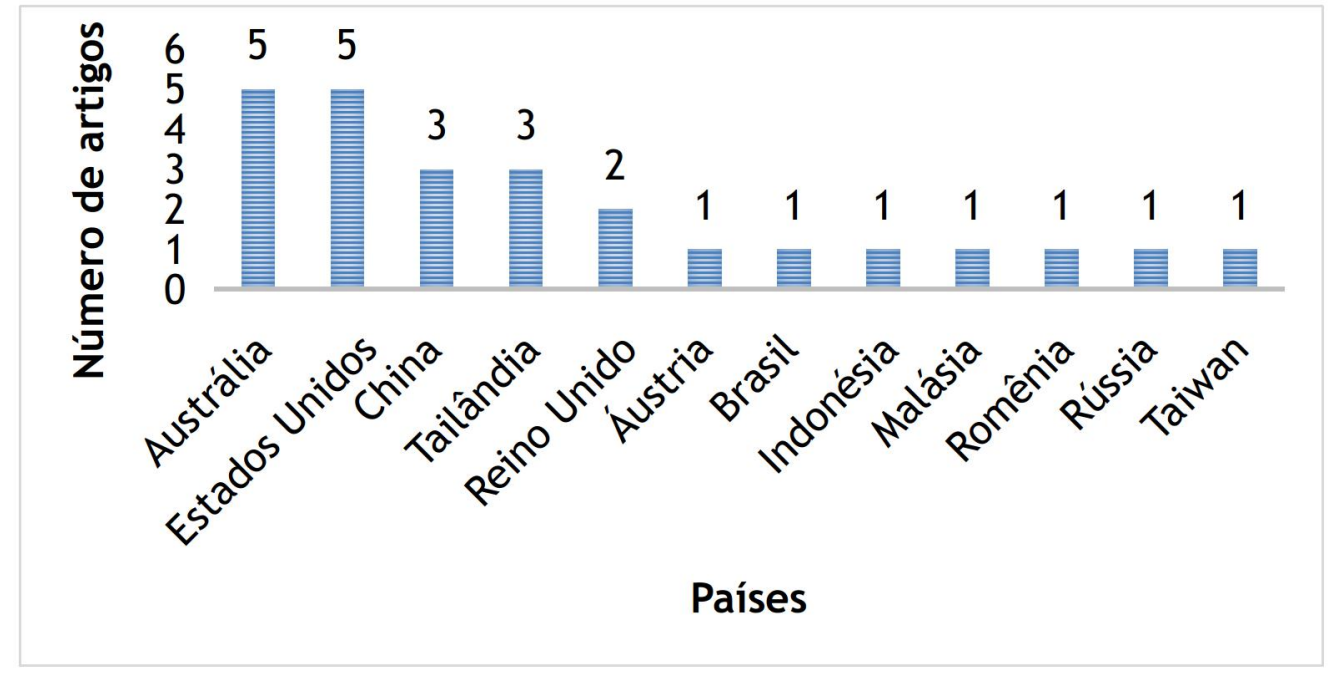

Figura 5 - Quantidade de artigos por países

Foi observado que, nos artigos publicados pelos autores Dhaval Vyas e Stephen Snow, a análise foi realizada sobre uma única base de dados nos artigos Vyas et al. [A02], Snow e Vyas [A03] e Vyas et al. [A05]. Foi entendido como mesma base de dados com a utilização dos mesmos dados coletados, porém, os resultados foram divididos, categorizados e apresentados em diferentes aspectos.

Em Vyas et al. [A02], foram analisadas as práticas e as estratégias utilizadas para economizar dinheiro. Em Snow e Vyas [A03] a razão para uso e o não uso de tecnologia para apoio PFF, assim como a análise do uso e da experiência dos usuários com os sistemas de informação no PFF no Vyas et al. [A05].

No artigo Snow e Vyas [A04] foi conduzido um novo estudo de caso com a mesma metodologia adotada (entrevistas com famílias) nos estudos Vyas et al. [A02], Snow e Vyas [A03] e Vyas et al. [A05]. Entretanto, o objetivo do Snow e Vyas [A04] foi entender se as atividades do PFF eram realizadas colaborativamente, os sistemas de informação, problemas enfrentados e propostas de requisitos funcionais para apoiar PFF.

\subsection{Sistemas de Informação para Planejamento Financeiro Familiar}

Os autores apresentaram diversos sistemas de informação (SI), dentre eles foram apresentadas ferramentas, softwares, aplicativos, frameworks, modelos conceituais de SI, requisitos funcionais e não funcionais para SI etc. Conforme Seção 4.4 Análise e Classificação, os SI foram categorizados de acordo com o uso e aplicação nos artigos:

SI citados pelos autores;

SI desenvolvido pelos autores;

SI utilizados em estudos de caso;

SI utilizados por participantes de entrevista e

Requisitos funcionais e não funcionais para SI.

A Tabela 9 apresenta a classificação dos sistemas de informação identificados e o código do artigo em que o SI foi encontrado. A maior parte dos SI que foram citados pelos autores, somam um total de 14 artigos (36,84\% dos SI). Porém, estes artigos não 
apresentaram detalhamento das funcionalidades e recursos destes sistemas de informação, sendo estes SI citados como exemplos nos estudos primários.

Tabela 9 - Categorização dos sistemas de informação identificados

\begin{tabular}{|l|l|l|}
\hline Tipos de sistemas de informação & $\begin{array}{l}\text { Artigos em que foram } \\
\text { apresentados }\end{array}$ \\
\hline SI citados pelos autores & A03; A04; A05; A07; A08; A09; \\
& $\begin{array}{l}\text { A10; A13; A16; A17; A18; A19; } \\
\text { A21; A22 }\end{array}$ \\
\hline SI desenvolvido pelos autores & $\begin{array}{l}\text { A06; A07; A08; A09; A10; A11; } \\
\text { A12; A14; A15; A17; A19; A21; } \\
\text { A23 }\end{array}$ & A22 \\
\hline SI utilizados em estudos de caso & A01; A05; A18 & \\
\hline $\begin{array}{l}\text { SI utilizados por participantes de } \\
\text { entrevista }\end{array}$ & A01; A02; A03; A04; A05; A11; \\
\hline $\begin{array}{l}\text { Requisitos funcionais e não funcionais } \\
\text { para SI }\end{array}$ & A18 \\
\hline
\end{tabular}

Na Figura 6 são apresentados os sistemas de informação citados pelos autores, com a quantidade de vezes que foram citados correspondendo ao código do artigo. $\mathrm{O}$ Mint foi o sistema de informação mais citado com o total de 9 citações, seguido pelo Quicken com 6 citações.

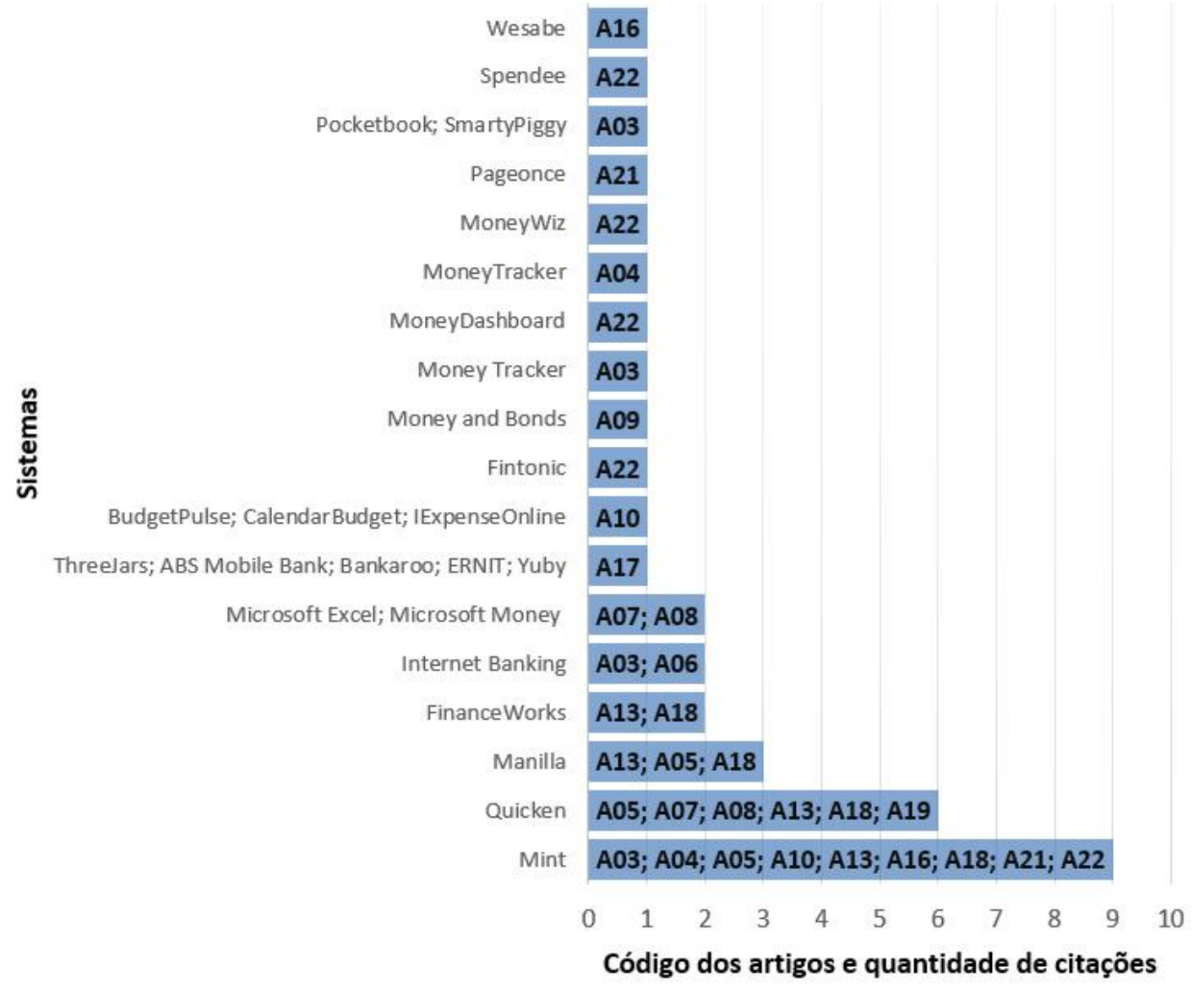


Figura 6 - Sistemas de informação citados pelos autores

Para maior entendimento dos sistemas de informação citados, foram analisadas as funcionalidades e recursos dos SI com mais de uma citação pelos autores. Os sistemas Manilla, FinanceWorks e Microsoft Money foram descontinuados. Internet Banking é um termo genérico utilizado para diversas aplicações fornecidas por instituições financeiras, como bancos e cooperativas. Como não foram especificados a qual instituição financeira faziam parte, não foi possível analisá-los. Igualmente o Microsoft Excel, que é um sistema de planilha eletrônica que cada usuário pode criar e customizar a seu modo.

Desta forma, foram analisados os sistemas Mint e Quicken que apresentaram um maior número de citações. Como estes sistemas de informação não estão disponíveis no Brasil, não foi possível ter acesso total a eles, as informações foram coletadas nos sites oficiais dos desenvolvedores ${ }^{2}$.

Para facilitar a visualização e compreensão, foram analisados de acordo com as dimensões do modelo 3C de colaboração proposto por Fuks et al. (2011). A Tabela 10 apresenta as funcionalidades e recursos dos sistemas Mint e Quicken de acordo com as dimensões do modelo 3C. Por mais que os sistemas de informação ofereçam recursos que poderiam dar suporte ao modelo, faltam recursos importantes para ser um sistema colaborativo, como por exemplo, permitir a criação e a configuração de um grupo familiar, incluindo acesso de mais membro da família e controle de perfis.

Tabela 10 - Análise dos sistemas de informação com o modelo $3 \mathrm{C}$ de colaboração

\begin{tabular}{|c|c|c|c|}
\hline & Funcionalidades & Mint & Quicken \\
\hline \multirow{8}{*}{ Coordenação } & $\begin{array}{l}\text { Criação e configuração de um grupo } \\
\text { familiar. }\end{array}$ & $\mathrm{x}$ & $\mathrm{X}$ \\
\hline & Controle de perfis e usuários. & $\mathrm{x}$ & $\mathrm{x}$ \\
\hline & $\begin{array}{l}\text { Controle de gastos por membro da } \\
\text { família. }\end{array}$ & $x$ & $\sqrt{ }$ \\
\hline & Controle de receitas e despesas. & $\sqrt{ }$ & $\sqrt{ }$ \\
\hline & Criação de orçamento previsto. & $\sqrt{ }$ & $\sqrt{ }$ \\
\hline & Controle de recibos. & $\sqrt{ }$ & $\sqrt{ }$ \\
\hline & Controle de metas financeiras. & $\sqrt{ }$ & $\mathrm{x}$ \\
\hline & Controle de investimentos. & $\sqrt{ }$ & $\sqrt{ }$ \\
\hline \multirow{2}{*}{ Cooperação } & Lançamento de receitas e despesas. & $\sqrt{ }$ & $\sqrt{ }$ \\
\hline & Compartilhamento de acesso a contas. & $\mathrm{x}$ & $\mathrm{x}$ \\
\hline \multirow{6}{*}{ Comunicação } & Lembretes de contas a vencer. & $\sqrt{ }$ & $\sqrt{ }$ \\
\hline & Lembretes de saldo em conta baixo. & $\sqrt{ }$ & $\mathrm{x}$ \\
\hline & $\begin{array}{l}\text { Apresentação da situação financeira } \\
\text { (contas, cartões de créditos). }\end{array}$ & $\sqrt{ }$ & $\sqrt{ }$ \\
\hline & Alerta quando exceder o orçamento. & $\sqrt{ }$ & $\sqrt{ }$ \\
\hline & Apresentação de gastos por categorias. & $\sqrt{ }$ & $\sqrt{ }$ \\
\hline & Dicas de economia. & $\sqrt{ }$ & $\mathrm{x}$ \\
\hline
\end{tabular}

\footnotetext{
${ }^{2}$ Mint: https://mint.intuit.com/

Quicken: https://www.quicken.com/
} 
Alguns sistemas de informação foram apresentados como resultados de pesquisa exploratória, através de entrevistas e questionários, sendo utilizados em caráter pessoal e/ou familiar. Os sistemas de informação utilizados por participantes em entrevistas são apresentados na Tabela 11.

Tabela 11 - Sistemas utilizados por participantes das entrevistas

\begin{tabular}{|l|l|}
\hline $\begin{array}{l}\text { Código dos } \\
\text { artigos }\end{array}$ & Sistemas \\
\hline A01; A05; A18 & Planilhas Eletrônicas. \\
\hline A01 & $\begin{array}{l}\text { Sistema dos cartões de crédito; Microsoft Money; Mint; } \\
\text { Quicken. }\end{array}$ \\
\hline A05 & Internet Banking. \\
\hline
\end{tabular}

Dentre os artigos, 13 deles apresentaram sistema de informação, framework ou um modelo conceitual desenvolvido pelos autores. O sistema Toshl Budgeting App é um aplicativo para gerenciar receitas e despesas no celular, ele foi aplicado em um ensaio controlado no artigo Angel [A22], porém não foi desenvolvido pelos autores, dessa forma, ele não foi agrupado com os demais sistemas de informação. Na Tabela 12 são apresentados os SI de acordo com o artigo relacionado. Os termos entre parênteses ("), foram adotados pelos autores em seus estudos, o entendimento é que eles fazem parte do planejamento financeiro familiar.

Tabela 12 - Sistemas de informação desenvolvidos pelos autores

\begin{tabular}{|c|c|}
\hline $\begin{array}{l}\text { Código } \\
\text { dos } \\
\text { artigos }\end{array}$ & Sistemas de informação \\
\hline A06 & Arquitetura de um SI para "gestão agregada de patrimônio". \\
\hline A07 & $\begin{array}{l}\text { Modelo conceitual para auxiliar famílias a realizarem o } \\
\text { planejamento financeiro com suporte de tomada de decisão, } \\
\text { adotaram o modelo de Simon do processo de tomada de decisão } \\
\text { com um quadro para um modelo FFP. A base de decisão utiliza } \\
\text { agentes inteligentes e tecnologia de serviços da } W E B \text { - Evolução } \\
\text { do Artigo A06. }\end{array}$ \\
\hline A08 & $\begin{array}{l}\text { Melhoria do SI desenvolvido no artigo A07, com aplicação de } \\
\text { novas tecnologias e integração de mais serviços. }\end{array}$ \\
\hline A09 & $\begin{array}{l}\text { HBKF: Framework orientado a aspectos para "escrituração da } \\
\text { casa". }\end{array}$ \\
\hline A10 & Estrutura conceitual da "contabilidade da casa". \\
\hline A11 & Finansialku: Software para gerenciar "finanças pessoais". \\
\hline A12 & $\begin{array}{l}\text { SI de gestão de planejamento financeiro pessoal com funções de } \\
\text { planejamento financeiro, que inclui contabilidade, orçamento e } \\
\text { monitoramento. }\end{array}$ \\
\hline A14 & $\begin{array}{l}\text { Framework com vários tipos de controles financeiros de acordo } \\
\text { com características pessoais, informações demográficas e } \\
\text { eventos críticos. }\end{array}$ \\
\hline A15 & $\begin{array}{l}\text { SI automatizado para pagar e gerenciar faturas com o menor } \\
\text { tempo possível. }\end{array}$ \\
\hline
\end{tabular}

iSys: Revista Brasileira de Sistemas de Informação (iSys: Brazilian Journal of Information Systems) 


\begin{tabular}{|l|l|}
\hline A17 & $\begin{array}{l}\text { KeptAom: SI de gestão de poupança de longo prazo para } \\
\text { crianças. }\end{array}$ \\
\hline A19 & $\begin{array}{l}\text { Personal Choice Point: SI de planejamento financeiro que } \\
\text { aborda decisões financeiras, que permite o usuário explorar os } \\
\text { impactos de suas decisões em outros objetivos de vida. }\end{array}$ \\
\hline A21 & $\begin{array}{l}\text { Aplicativo móvel que implementa mecanismo de notificação e } \\
\text { alertas diário para planejamento financeiro pessoal. }\end{array}$ \\
\hline A23 & $\begin{array}{l}\text { Esquema conceitual baseado na contabilidade que inclui } \\
\text { rendimentos, despesas, investimento, poupança e permite a } \\
\text { gestão atual e estratégica das finanças familiares pessoais. }\end{array}$ \\
\hline
\end{tabular}

No decorrer da leitura dos artigos, foram apresentados requisitos funcionais e não funcionais pelos autores. Parte dos requisitos apresentados, foram levantados por meio da apresentação de ideias dos participantes entrevistados nos estudos com abordagem exploratória.

$\mathrm{Na}$ Tabela 13 são apresentados os requisitos funcionais e não funcionais. Os requisitos funcionais e não funcionais apresentados trazem informações relevantes que podem ser utilizadas no desenvolvimento de sistema de informação para planejamento financeiro familiar.

Tabela 13 - Requisitos funcionais e não funcionais

\begin{tabular}{|c|c|}
\hline $\begin{array}{l}\text { Código } \\
\text { dos } \\
\text { artigos }\end{array}$ & Requisitos funcionais/não funcionais \\
\hline $\mathrm{A} 01$ & $\begin{array}{l}\text { Possuir funcionalidade para que as pessoas compartilhem seu } \\
\text { progresso, podendo criar canais para prestação de contas, } \\
\text { motivando-as e fazê-las sentir responsáveis perante o SI; } \\
\text { Possibilitar a criação de novas metas para serem atingidas. }\end{array}$ \\
\hline A02 & $\begin{array}{l}\text { Criar aplicativo para gerenciar o orçamento, gravação e apresentação } \\
\text { de dados semelhante aos aplicativos de saúde e fitness, como perda } \\
\text { de peso. }\end{array}$ \\
\hline A03 & $\begin{array}{l}\text { Manter o engajamento do usuário e para conseguir criar uma } \\
\text { abordagem mais visual; } \\
\text { Manter um segredo: ter funcionalidade que possibilite esconder o } \\
\text { dinheiro poupado, ocultar o saldo da conta, bloquear o acesso a } \\
\text { conta até uma determinada data; } \\
\text { Integrar materiais físicos: como caixa de recebimento, na qual os } \\
\text { usuários depositariam os recibos das compras que fizeram com } \\
\text { dinheiro. A caixa de recibo iria fotografar o recibo - identificar os } \\
\text { totais e manter um registro do total dos recibos depositados na } \\
\text { caixa. }\end{array}$ \\
\hline
\end{tabular}




\begin{tabular}{|l|l|}
\hline A04 & Rastrear as finanças automaticamente; \\
& Categorizar as finanças em gráficos em forma de pizza; \\
& Gerenciar as finanças através de um calendário; \\
& Permitir a criação de lembretes para contas a vencer; \\
& Controlar gastos por membro da família em viagens. \\
\hline A05 & Permitir a verificação automática de recibos em vez de inseri-los \\
& manualmente, através do conceito de livro de conta doméstica \\
& digital \\
\hline A11 & Oferecer características "amigáveis", permitindo que os usuários \\
& gerenciem seus aspectos financeiros, de modo fácil, divertido e \\
& inteligente; \\
& Ser capaz de verificar e salvar contas; \\
& Categorizar as "transações financeiras"; \\
& Ser flexível para criar e fácil de monitorar um orçamento; \\
& Ajudar os usuários a alcançar seus objetivos de poupança; \\
& Ser fácil de acompanhar os investimentos; \\
& Acompanhar o andamento do dinheiro; \\
& Ser uma aplicação segura. \\
\hline Permitir que os usuários categorizem potes de dinheiro, destinados a \\
"razões sentimentais", a "dias chuvosos", a "aprender e cometer \\
erros"; \\
Permitir privacidade em casos em que há acesso por mais de uma \\
pessoa, por exemplo: acesso a saldos e histórico de pagamentos \\
separados da visualização de compras individuais para permitir às \\
mães para se sentir conectada com seus filhos, porém mantendo a \\
privacidade, entre outros.
\end{tabular}

\subsection{Estratégias}

Além dos sistemas de informação, foram apresentadas estratégias adotadas no planejamento financeiro pessoal e/ou familiar. As estratégias são atividades práticas (empíricas) e técnicas utilizadas para o gerenciamento e o planejamento financeiro, nos artigos foram apresentadas sem auxílio de recursos computacionais, em muitos casos foram desenvolvidas pelas próprias famílias para realizar o planejamento financeiro familiar. A Tabela 14 apresenta as estratégias mencionadas pelos autores.

Tabela 14 - Estratégias

\begin{tabular}{|l|l|}
\hline $\begin{array}{l}\text { Código dos } \\
\text { artigos }\end{array}$ & Estratégias \\
\hline $\begin{array}{l}\text { A02; A05; A16; } \\
\text { A18; A23 }\end{array}$ & Envelopes ou potes de dinheiro categorizados por despesas. \\
\hline A04; A05; A18 & $\begin{array}{l}\text { Diário, agenda ou caderno com o detalhamento de todas as } \\
\text { atividades da família, incluindo pagamento de despesas. }\end{array}$ \\
\hline A02; A05; A18 & Vale compra ou cupons de descontos. \\
\hline A05; A14; A20 & $\begin{array}{l}\text { Gerenciamento ou orçamento mental, em alguns casos com o } \\
\text { uso de lembretes visuais. }\end{array}$ \\
\hline A04; A05 & Organizador de parede ou pastas com divisórias para \\
\hline
\end{tabular}

isys: Revista Brasileira de Sistemas de Informação (isys: Brazilian Journal of Information Systems) 


\begin{tabular}{|c|c|}
\hline & $\begin{array}{l}\begin{array}{l}\text { categorizar contas a serem pagas e outros itens como } \\
\text { comprovantes. }\end{array} \\
\end{array}$ \\
\hline A05; A18 & Calendário com anotações de atividades financeiras \\
\hline A04; A05 & $\begin{array}{l}\text { Reunião financeira mensal com a família para discutir as } \\
\text { finanças. }\end{array}$ \\
\hline A02 & $\begin{array}{l}\text { Reunir todo o rendimento em uma conta conjunta e depois } \\
\text { pagar as despesas. }\end{array}$ \\
\hline $\mathrm{A} 02$ & Guardar o dinheiro fora do alcance da visão. \\
\hline A04 & $\begin{array}{l}\text { Divisão da responsabilidade para realizar a administração } \\
\text { financeira, como em outras atividades domésticas. }\end{array}$ \\
\hline A04 & $\begin{array}{l}\text { Atribuição do planejamento financeiro a curto-prazo para um } \\
\text { membro e de longo-prazo para outro. }\end{array}$ \\
\hline A04 & $\begin{array}{l}\text { Na realização de compras um membro era responsável pela } \\
\text { pesquisa de preços, depois escolhiam a melhor opção e o outro } \\
\text { ficava responsável em negociar e comprar. }\end{array}$ \\
\hline A05 & Planilhas escritas à mão. \\
\hline A05 & $\begin{array}{l}\text { Conta conjunta para atingir objetivos da família e conta } \\
\text { individual para fins pessoais. }\end{array}$ \\
\hline A14 & Utilização de conta bancária em conjunto. \\
\hline A17 & $\begin{array}{l}\text { Técnica de gerenciamento de dinheiro para ensinar crianças } \\
\text { sobre dinheiro, nomeada Três Jarros (poupança, gastos e } \\
\text { compartilhamento). O objetivo do jarro de poupança é coletar } \\
\text { dinheiro para um investimento futuro, enquanto o de gastos é } \\
\text { usar o dinheiro para suas próprias despesas. O objetivo do jarro } \\
\text { de compartilhamento é ensinar às crianças que elas devem doar } \\
\text { dinheiro para instituições de caridade ou pessoas necessitadas. }\end{array}$ \\
\hline
\end{tabular}

A inclusão das estratégias na pesquisa, traz a perspectiva social para sistemas de informação por meio da apresentação das necessidades da família na realização do PFF. Estas estratégias podem ser incorporadas em SI como recursos e funcionalidades, dentre elas, recursos colaborativos que podem ser vistos sendo utilizados pelas famílias.

\section{Discussão}

Por meio da avaliação dos 23 artigos resultantes, foi possível responder as questões de pesquisa propostas para o mapeamento sistemático da literatura e levantar discussões importantes na área do planejamento financeiro familiar. A discussão a respeito de cada uma das questões é apresentada.

QP1: "Quais são os sistemas de informação, que apoiam o planejamento financeiro pessoal elou familiar?"

A extração de dados resultou em 40 sistemas de informação para o planejamento financeiro, dentre estes, $26(65 \%)$ sistemas de informação foram citados pelos autores, $13(32,5 \%)$ desenvolvidos pelos autores e $1(2,5 \%)$ utilizado em um estudo de caso desenvolvido por terceiro. Entretanto, somente $6(15 \%)$ sistemas de informação foram utilizados, sendo que a adesão por sistemas de informação de PFF é baixa.

Embora existam sistemas de informação para PFF, baseados em computador, no artigo A07, os autores argumentam que estes têm o foco em uma área do PFF (como previsão de receitas e despesas, investimentos, definição de metas) e faltam recursos 
com características proativa e reativa (como recomendar ações necessárias para melhorar o PFF).

No estudo Kaye et al. [A18], os usuários entrevistados não eram usuários regulares de sistema de informação para PFF, em alguns casos, criaram planilhas eletrônicas. Dentre os motivos apresentados por estes, estava a falta de confiança na segurança da informação, inconveniência de registrar todas as contas e frustações relacionadas a funcionalidades, como a categorização automática de despesas. Em contrapartida, este resultado traz oportunidades, tanto para repensar sistemas de informação, como para o design de novas experiências na interação financeira, como incluir componentes emocionais e pessoais, pois estas envolvem e influenciam a decisão financeira.

Os autores do Snow e Vyas [A03] relataram que dentre os 15 participantes entrevistados em seu estudo, 5 relataram ter utilizado sistema de informação para PFF, porém, todos deixaram de utilizar após um curto período. A razão apresentada estava relacionada ao cansaço de acompanhar as despesas regularmente e/ou sentir-se no controle suficiente de seus gastos. Complementando, os motivos apresentados no artigo Epstein et al. [A01] são: atingimento da meta desejada; outras pessoas não estavam utilizando; tédio; quando o sistema de informação não supre novas necessidades e falta de motivação.

Foram descritas no Epstein et al. [A01] três classes de motivações para que usuários utilizem um novo sistema de informação de PFF. São elas: mudança de comportamento (como atingir uma nova meta), registro de um determinado comportamento e curiosidade por algo novo. Seguindo nessa linha, em Vyas et al. [A02] os autores acrescentam que a motivação para poupar dinheiro, está relacionada a desejos e/ou para obter uma segurança financeira no futuro.

QP2: "Quais são as estratégias para realizar o planejamento financeiro pessoal elou familiar?"

As estratégias apresentadas pelos autores estavam relacionadas a atividades práticas, realizadas no dia a dia, algumas estratégias bem difundidas como a técnica de categorização das despesas em envelopes, citadas em 5 artigos: Vyas et al. [A02], Vyas et al. [A05], Krumme et al. [A16], Kaye et al. [A18] e Gorshkova et al. [A23], outras estratégias simples criadas pelos usuários, como a utilização de diários/agendas/cadernos para organizar o pagamento de despesas.

O artigo Muske e Winter [A20], revelou que responsáveis por administrar o PFF, utilizavam regularmente uma estratégia criada de forma sistêmica (com regras definidas pela família ou pelo responsável). Entretanto, raramente utilizavam técnicas recomendadas em livros didáticos. Em grande parte, possuíam alguns recursos que imitavam as técnicas, mas com elementos que foram criados exclusivamente pelo responsável, com o objetivo de minimizar a carga do gerenciamento financeiro mental e o tempo despendido para esta atividade.

Complementando, em muitos casos, os responsáveis procuraram maneiras de minimizar a necessidade de documentação por escrito, utilizando a gestão mental, pois estavam mais preocupados com questões de curto prazo, ou seja, atividades relacionadas ao planejamento das finanças do dia a dia. 
QP3: "O sistema de informação ou a estratégia adotada, apresenta requisitos colaborativos, para o desenvolvimento do planejamento financeiro pessoal elou familiar?"

A maioria dos sistemas de informação mencionados pelos autores não descreveram requisitos colaborativos. Foram analisados os dois sistemas de informação mais citados pelos autores, Mint e o Quicken. Esses SI apresentaram várias funcionalidades que poderiam atender as dimensões do modelo $3 \mathrm{C}$, porém ainda faltam recursos para que seja criado o grupo familiar, assim como permitir que toda a família como acompanhar e participar ativamente no PFF.

No artigo Palakvangsa-Na-Ayudhya et al. [A17] foi apresentado um sistema denominado KeptAom, que envolve a gestão de poupança de longo prazo para crianças com o engajamento e colaboração da família, pois o processo de aprendizagem da gestão do dinheiro deve iniciar durante a infância e deve ter o envolvimento dos pais orientando seus filhos.

Outros sistemas de informação citados no artigo Palakvangsa-Na-Ayudhya et al. [A17] envolviam a colaboração em torno da família são: ThreeJars, ASB Mobile Banking, Bankaroo, Yuby e ERNIT. Nestes sistemas, o objetivo é a educação financeira de crianças com o envolvimento dos pais.

Além dos sistemas de informação citados nos artigos, alguns artigos apresentaram requisitos funcionais para um SI de planejamento financeiro. Estes requisitos foram classificados e dentre estes, os que envolviam colaboração da família no planejamento financeiro são:

Epstein et al. [A01]: Compartilhar progresso financeiro;

Snow e Vyas [A04]: Controlar gastos por membro da família em viagens; e

Kaye et al. [A18]: Controlar privacidade para mais de um usuário, como acesso a saldos e histórico de pagamentos separados da visualização de compras individuais.

A colaboração pode ser observada de uma forma natural nas estratégias adotadas pelas famílias nos artigos Snow e Vyas [A04] e Vyas et al. [A05], como a reunião financeira realizada mensalmente e a agenda com atividades e compromissos financeiros da família. A colaboração estava presente no PFF, diretamente relacionada com as atividades domésticas e em muitos casos, as estratégias eram indispensáveis para a gestão de toda a família.

O autor do artigo Snow e Vyas [A04] acrescenta que, o foco de grande parte do design de tecnologia na área de finanças doméstica é o desenvolvimento de novos sistemas de informação, destinadas a ajudar as pessoas no orçamento e no planejamento das finanças pessoais, porém mesmo que estes sistemas de informação ofereçam funcionalidades impressionantes para o usuário e desempenhem um papel importante na administração do dinheiro em escala pessoal, descobriram que administrar as finanças da família era muitas vezes um processo mais colaborativo. Assim, os autores do artigo Vyas et al. [A02] argumentam que existe potencial para aplicativos que promovam, incentivem e apoiem estratégias na gestão financeira, que observaram sendo utilizadas pelas famílias.

QP: "Como tem sido realizado o planejamento financeiro pessoal elou familiar?" - 
Existem vários sistemas de informação para o planejamento das finanças de indivíduos e da família, porém no dia a dia grande parte destes, criam suas próprias estratégias para realizar o planejamento financeiro, deixando de lado em muitos casos sistemas de informação.

Algumas razões foram levantadas para justificar tal comportamento, tais como: o PFF ocorre de forma colaborativa e o sistema de informação não contempla esta necessidade; atingimento da meta ou objetivo estipulado, isso ocorre quando há necessidade de uma mudança de comportamento (quitar dívidas, comprar algo novo, entre outros); tédio e/ou cansaço para registrar as atividades financeiras; frustrações relacionadas a funcionalidades, entre outros.

Foram analisados os sistemas de informação mais citados pelos autores (Mint e Quicken) de acordo com o modelo 3C de colaboração, com o objetivo de verificar se tinham funcionalidades e recursos para apoiar a família no processo de PFF. Porém, mesmo com vários recursos, não apresentaram funcionalidades colaborativas. Isto vai contra o que foi observado em estudos exploratórios, pois o PFF em muitos casos é realizado colaborativamente.

Entretanto, essa descoberta vai de encontro com o desafio na área de sistemas de informação, em que devem ser compreendidas as necessidades do usuário, neste caso a família, para então propor um sistema de informação que a apoie neste processo. Além do desafio, este resultado apresenta uma lacuna de estudos na área de sistemas colaborativos para planejamento financeiro doméstico.

\section{Considerações finais}

O planejamento financeiro familiar pode envolver toda a família ou limitar o indivíduo, diferentes tipos de sistemas de informação podem ser utilizados nesse processo, planilhas eletrônicas ou estratégias desenvolvidas pela família, como administração dos recursos por meio de envelope categorizados, quadro financeiro, entre outros.

A busca inicial retornou 1722 artigos, destes, 52 foram selecionados após a aplicação dos critérios de inclusão e 23 foram selecionados para a análise e extração dos dados com base nos critérios de exclusão. Com base na leitura completa e análise estes artigos apresentaram sistemas de informação e estratégias utilizadas no processo de planejamento financeiro familiar.

Dentre os 26 sistemas de informação citados pelos autores nos artigos, somente 6 deles eram utilizados por indivíduos e famílias no dia a dia, apresentados em estudos que realizaram pesquisa exploratória por meio de questionários e entrevistas. Dessa forma, foi observado que em muitos casos o foco estava no uso de estratégias, que foram desenvolvidas para auxiliar no planejamento financeiro familiar como: a utilização de envelopes categorizados por despesas, agenda com compromissos financeiros, entre outros. Estes resultados corroboram com as pesquisas dos autores Snow e Vyas (2015b) e Kaye et al. (2014) que concluíram que o PFF em muitos casos era um processo colaborativo.

Nesta pesquisa, foi utilizado o Modelo 3C para analisar os dois sistemas de informação mais citados (Mint e Quicken). Este modelo pode compreender e dar suporte às ferramentas para o desenvolvimento do PFF, deste modo, o grupo se caracteriza na família. Porém, os sistemas de informação não foram considerados 
colaborativos, pois faltam recursos para compreender todas as dimensões da colaboração como o acesso a mais de um membro da família.

A principal contribuição deste trabalho foi a análise de que a área de planejamento financeiro familiar, necessita de mais estudos no desenvolvimento de sistemas de informação. Estudos que visem incorporar as estratégias utilizadas como recursos computacionais e que motivem os usuários para que não deixem de utilizar o sistema após um curto período. Os resultados apresentados neste trabalho, vão de encontro ao desafio na área de sistemas de informação, em que devem ser compreendidas as questões sociais e impactos dos sistemas de informação na vida das pessoas. Desta forma, os resultados aqui apresentados podem ser utilizados para estudo na área de sistemas de informação.

Para trabalhos futuros, sugere-se a realização de uma pesquisa exploratória com usuários para a realização da triangulação de dados obtidos nesse estudo (MSL), por meio de entrevistas com especialistas na área de gerenciamento e planejamento financeiro e aplicação de questionários com usuários finais para o levantamento e validação de requisitos funcionais e não funcionais. Este levantamento de dados pode subsidiar o desenvolvimento de um sistema de informação para o planejamento financeiro familiar com recursos colaborativos.

\section{Agradecimentos}

Agradecimento ao apoio da UDESC/PROMOP - Programa de Bolsas de Monitoria de Pós-Graduação - pela concessão de bolsa de pós-graduação e a FAPESC - Termo de outorga número: 2019TR585 - Processo FAPESC 896/2019 do Edital de Chamada Pública FAPESC no 04/2018 e 027/2020 - Apoio à Infraestrutura para Grupos de Pesquisa da UDESC.

\section{Referências}

Brito, L. S., Baptista, J., Silva, S., Braz, S., and Henrique, M. (2018). A importância da educação financeira nos contextos acadêmico e profissional: um levantamento de dados com alunos universitários. Anais In: IX SEGeT Simpósio de Excelência em Gestão e Tecnologia.

Boscarioli, C.; Araujo, R. M.; Maciel, R. S. P. (2017). I GranDSI-BR - Grand Research Challenges in Information Systems in Brazil 2016-2026. Special Committee on Information Systems (CE-SI). Brazilian Computer Society (SBC).

Buchinger, D., de Cavalcanti, G. A. S., and Hounsell, M. S. (2014). Mecanismos de busca acadêmica: uma análise quantitativa. Revista Brasileira de Computação Aplicada, 6(1), 108-120. [GS Search]

Cherobim, A. P. M. S., and Espejo, M. D. S. (2010). Finanças pessoais: conhecer para enriquecer. São Paulo: Atlas.

Fuks, H., Gerosa, M. A., and de Lucena, C. J. P. (2002). The development and application of distance learning courses on the internet. Open Learning: The Journal of Open, Distance and e-Learning. p. 23-38. [GS Search] 
Fuks, H., Raposo, A. B., Gerosa, M. A., Pimentel, M., Filippo, D., and Lucena, C. D. (2011). Teorias e modelos de colaboração. Pimentel, M. e Fuks, H. Sistemas colaborativos. Rio de Janeiro: Elsevier-Campus-SBC. [GS Search]

Gao, S., Wang, H., Xu, D., Wang, Y., Shen, W., and Yeung, S. (2006). Intelligent decision support for family financial planning. In Proceedings of the 39th Annual Hawaii International Conference on System Sciences (HICSS'06). IEEE. [GS Search]

Gonzalez Junior, I. P., Melo, E. R., and Silva, K. S. (2018). Orçamento Familiar Como Ferramenta De Auxílio No Gerenciamento Dos Recursos Financeiros De Pais Universitários. Ideias e Inovação-Lato Sensu, 4(3), 131. [GS Search]

Kaye, J. J., McCuistion, M., Gulotta, R., and Shamma, D. A. (2014). Money talks: tracking personal finances. In Proceedings of the SIGCHI Conference on Human Factors in Computing Systems. p. 521-530. [GS Search]

Kitchenham, A. B., Dyba, T., and Jorgensen, M. (2004). Evidence-based software engineering. In Proceedings of the 26th International Conference on Software Engineering. p. 273-281. doi: 10.1109/ICSE.2004.1317449 [GS Search]

Laudon, K. C. and Laudon, J. P. (2014). Sistemas de informação gerenciais. São Paulo: Pearson Education do Brasil, 2014.

Nicolaci-da-Costa, A. M., and Pimentel, M. (2011). Sistemas colaborativos para uma nova sociedade e um novo ser humano. Pimentel, M. and Fuks, H. (Orgs.). Sistemas colaborativos. Rio de Janeiro: Elsevier. [GS Search]

Pereira, R. and Baranauskas, M. C. C. (2017). Systemic and Socially Aware Perspective for Information Systems. Boscarioli, C.; Araujo, R. M.; Maciel, R. S. P. I GranDSIBR - Grand Research Challenges in Information Systems in Brazil 2016-2026. Special Committee on Information Systems (CE-SI). Brazilian Computer Society $(\mathrm{SBC})$.

Petersen, K., Vakkalanka, S., and Kuzniarz, L. (2015). Guidelines for conducting systematic mapping studies in software engineering: An update. Information and Software Technology, 64, 1-18. [GS Search]

Pimentel, M., Fuks, H., and Lucena, C. J. (2008). Um processo de desenvolvimento de sistemas colaborativos baseado no Modelo 3C: RUP-3C-Groupware. Anais do IV SBSI. SBSI, 7(1), 1-14. [GS Search]

Pimentel, M., Gerosa, M. A., Filippo, D., Raposo, A., Fuks, H., \& Lucena, C. J. P. D. (2006). Modelo 3C de Colaboração para o desenvolvimento de Sistemas Colaborativos. Anais do III Simpósio Brasileiro de Sistemas Colaborativos, 58-67. [GS Search]

Pires, V. (2006). Finanças pessoais fundamentos e dicas. Piracicaba: Editora Equilíbrio. [GS Search]

Santos, V. V., Tedesco, P. and Salgado, A. C. (2011). Percepção e contexto. Pimentel, M. and Fuks, H. (Orgs.). Sistemas Colaborativos. Rio de Janeiro: Elsevier-CampusSBC. ISBN 978-85-352-4669-8. [GS Search]

Serasa Experian. (2019). Inadimplência atinge 63 milhões de consumidores em março e bate recorde histórico, revela Serasa Experian. 
Snow, S., and Vyas, D. (2015a). Fixing the alignment: An exploration of budgeting practices in the home. In Proceedings of the 33rd Annual ACM Conference Extended Abstracts on Human Factors in Computing Systems. p. 2271-2276. [GS Search]

Snow, S., and Vyas, D. (2015b). Fostering collaboration in the management of family finances. In Proceedings of the Annual Meeting of the Australian Special Interest Group for Computer Human Interaction. p. 380-387. [GS Search]

Struwig, F. W., and Plaatjes, W. (2007). Developing a model to investigate the personal financial management knowledge of individuals: management. South African Journal of Economic and Management Sciences, 10(1), 21-32. [GS Search]

\section{Apêndice A - Referências dos artigos identificados no mapeamento sistemático da literatura}

A01. Epstein, D. A., Ping, A., Fogarty, J., and Munson, S. A. (2015). A lived informatics model of personal informatics. In Proceedings of the 2015 ACM International Joint Conference on Pervasive and Ubiquitous Computing. p. 731-742. doi: $\underline{10.1145 / 2750858.2804250}$ [GS Search]

A02. Vyas, D., Snow, S., Brereton, M., Dulleck, U., \& Boyen, X. (2015, February). Being thrifty on a $\$ 100 \mathrm{~K}$ wage: Austerity in family finances. In Proceedings of the 18th ACM Conference Companion on Computer Supported Cooperative Work \& Social Computing. p. 167-170. doi: 10.1145/2685553.2698998 [GS Search]

A03. Snow, S., and Vyas, D. (2015a). Fixing the alignment: An exploration of budgeting practices in the home. In Proceedings of the 33rd Annual ACM Conference Extended Abstracts on Human Factors in Computing Systems. p. 22712276. doi: $10.1145 / 2702613.2732808$ [GS Search]

A04. Snow, S., and Vyas, D. (2015b). Fostering collaboration in the management of family finances. In Proceedings of the Annual Meeting of the Australian Special Interest Group for Computer Human Interaction. p. 380-387. doi: $\underline{10.1145 / 2838739.2838746}$ [GS Search]

A05. Vyas, D., Snow, S., Roe, P., and Brereton, M. (2016). Social organization of household finance: Understanding artful financial systems in the home. In Proceedings of the 19th ACM Conference on Computer-Supported Cooperative Work \& Social Computing. p. 1777-1789. [GS Search]

A06. Gao, S., Wang, H., Wang, Y., Shen, W., and Yeung, S. (2005). Web-serviceagents-based family wealth management system. Expert Systems with Applications, 29(1), 219-228. [GS Search]

A07. Gao, S., Wang, H., Xu, D., Wang, Y., Shen, W., and Yeung, S. (2006). Intelligent decision support for family financial planning. In Proceedings of the 39th Annual Hawaii International Conference on System Sciences (HICSS'06). IEEE. [GS Search]

A08. Gao, S., Wang, H., Xu, D., and Wang, Y. (2007). An intelligent agent-assisted decision support system for family financial planning. Decision Support Systems, 44(1), 60-78. [GS Search]

A09. Rukhiran, M., and Netinant, P. (2017). Aspect-oriented approach for supporting house bookkeeping software design. In Proceedings of the 2017 International 
Conference on Software and e-Business. p. 49-54. doi: 10.1145/3178212.3178217 [GS Search]

A10. Rukhiran, M., and Netinant, P. (2017). The Concept Design of House Bookkeeping Software Using Aspect Oriented Approach. In Proceedings of the 2017 International Conference on Information Technology. p. 232-236. doi: 10.1145/3176653.3176667 [GS Search]

A11. Mumpunia, M., and Sukarnob, S. (2014). Design and Implementation Money Management Web Based Application for Personal and Family Proposed for CV. X. Procedia-Social and Behavioral Sciences, 115, 444-459. [GS Search]

A12. Weng, T. S., and Tseng, S. F. (2010). Design of a personal financial planning management information system. In 2010 IEEE International Conference on Advanced Management Science (ICAMS 2010), vol. 2, 73-78. IEEE. [GS Search]

A13. Lewis, M., and Perry, M. (2019). Follow the money: Managing personal finance digitally. In Proceedings of the 2019 CHI Conference on Human Factors in Computing Systems. p. 1-14. doi: 10.1145/3290605.3300620 [GS Search]

A14. Miotto, A. P. S., and Parente, J. (2015). Antecedents and consequences of household financial management in Brazilian lower-middle-class. Revista de Administração de Empresas, 55(1), 50-64. [GS Search]

A15. Popaa, S., Prosteana, G., Adama, A., and Dumitrescua, C. (2014). Household and personal management. Being part of the new generation. Procedia-Social and Behavioral Sciences, 124, 451-459. [GS Search]

A16. Krumme, C., Lee, K., and Ross, E. (2009). Concrete budgeting: A financial planning tool for intertemporal tradeoffs and just-in-time information. In 2009 IEEE 13th International Symposium on Consumer Electronics. p. 696-698. IEEE. [GS Search]

A17. Palakvangsa-Na-Ayudhya, S., Pongchandaj, S., Kriangsakdachai, S., and Sunthornwutthikrai, K. (2017). KeptAom: Savings management system to increase long term savings behavior of children. In TENCON 2017-2017 IEEE Region 10 Conference. p. 2247-2252. IEEE. [GS Search]

A18. Kaye, J. J., McCuistion, M., Gulotta, R., and Shamma, D. A. (2014). Money talks: tracking personal finances. In Proceedings of the SIGCHI Conference on Human Factors in Computing Systems. p. 521-530. doi: 10.1145/2556288.2556975 [GS $\underline{\text { Search }}]$

A19. Fano, A., and Kurth, S. W. (2003). Personal choice point: helping users visualize what it means to buy a BMW. In Proceedings of the 8th international conference on Intelligent user interfaces. p. 46-52. doi: 10.1145/604045.604057 [GS Search]

A20. Muske, G., and Winter, M. (2004). Personal financial management education: An alternative paradigm. Journal of Financial Counseling and Planning, 15(2), 79-88. [GS Search]

A21. Yusof, S. M., and Lokman, S. F. S. S. (2014). Personal financial planner: A mobile application that implementing forward chaining technique for notification mechanism. In 2014 IEEE Symposium on Computer Applications and Industrial Electronics (ISCAIE). p. 65-69. IEEE. [GS Search] 
A22. Angel, S. (2018). Smart tools? A randomized controlled trial on the impact of three different media tools on personal finance. Journal of Behavioral and Experimental Economics, 74, 104-111. [GS Search]

A23. Gorshkova, N. V., Mytareva, L. A., Perekrestova, L. V., Glushchenko, A. V., and Fisher, O. V. (2015). System of Family Budgeting as a Methodological Basis for Personal Accounting and Guarantee for Growth of Financial Literacy of the Russians. Mediterranean Journal of Social Sciences, 6(5), 413. [GS Search] 